\title{
The AAP and the SPR Child Abuse Committee issue a clinical report on 'Evaluating children with fractures for child physical abuse'
}

\author{
Jeannette M. Perez-Rossello
}

Received: 21 January 2014 / Accepted: 23 January 2014 / Published online: 14 February 2014

(C) Springer-Verlag Berlin Heidelberg 2014

After bruises, fractures are the most common injury and sometimes the only reliable indication that physical abuse has occurred. A multidisciplinary team approach is needed for optimal evaluation in cases of suspected child abuse. To some observers, this may seem to be a modern phenomenon, but this approach has its origins in the historical collaboration between the pediatric radiologist Fredrick Silverman, MD, and the pediatrician Henry Kempe, MD, as well as others, as described in the landmark article, "The battered-child syndrome" [1]. Child abuse pediatricians are now at the center of the assessment of suspected child maltreatment, and they regularly rely upon pediatric radiologists to inform their systematic analysis of the medical aspects of these often challenging cases. When fractures are encountered in living and deceased children, this collaboration may also include orthopedic surgeons, endocrinologists and pathologists to explore a variety of differential considerations, including metabolic bone diseases and genetic syndromes that mimic child abuse. Pediatric radiologists are vital to this assessment in order to characterize the type, age, location and distribution of the osseous injuries, as well as to assess for the presence of underlying bone disease. Their involvement is also important to ensure that images are acquired in accord with the highest professional standards [2-6]. Not only do pediatric radiologists contribute to an accurate diagnosis, they offer critical medical evidence that aids in the investigation and adjudication of cases of alleged child abuse.

Over the last several years, the American Academy of Pediatrics Committee on Child Abuse has collaborated with the Child Abuse Committee of the Society for Pediatric

J. M. Perez-Rossello $(\bowtie)$

Department of Radiology, Boston Children's Hospital,

300 Longwood Ave., Main 2, Boston, MA 02115, USA

e-mail: jeannette.perez-rossello@childrens.harvard.edu
Radiology in the preparation of a clinical report reviewing our current understanding of inflicted skeletal injuries as well as other conditions that present with fractures. The result of this effort is the clinical report "Evaluating children with fractures for child physical abuse," which was recently published in Pediatrics (http://pediatrics.aappublications.org.ezpprod1.hul.harvard.edu/content/133/2/e477.full.pdf) [7]. This clinical report will aid physicians in developing an evidencebased differential diagnosis and performing the appropriate evaluation when assessing a child with fractures.

Conflict of interest None.

\section{References}

1. Kempe C, Silverman F, Steele B et al (1962) The battered-child syndrome. JAMA 181:17-24

2. American College of Radiology (2011) ACR-SPR practice guideline for skeletal surveys in children revised 2011 (resolution 54)*. American College of Radiology, Reston, VA. http://www.acr.org/ /media/ 9bdcdbee99b84e87baac2b1695bc07b6.pdf. Accessed 9 Jan 2014

3. Meyer JS, Gunderman R, Coley BD et al (2011) ACR appropriateness criteria on suspected physical abuse-child. J Am Coll Radiol 8: $87-94$

4. American Academy of Pediatrics, Section on Radiology (2009) Diagnostic imaging of child abuse. Pediatrics 123:1430-1435

5. (2008) Standard for skeletal surveys in suspected non-accidental injury (NAI) in children. The British Society of Paediatric Radiology. http:/ www.kindesmisshandlung.de/mediapool/32/328527/data/ BritPedRad-SS.pdf. Accessed 18 Jan 2014

6. (2008) Standards for radiological investigations of suspected nonaccidental injury. The Royal College of Radiologists and Royal College of Paediatrics and Child Health. http:/www.rcr.ac.uk/docs/ radiology/pdf/RCPCH_RCR_final.pdf. Accessed 9 Jan 2014

7. Flaherty EG, Perez-Rossello JM, Levine MA, Hennrikus WL, and the American Academy of Pediatrics Committee on Child Abuse and Neglect, Section on Radiology, Section on Endocrinology, and Section on Orthopaedics, and The Society for Pediatric Radiology (2014) Evaluating children with fractures for child physical abuse. Pediatrics 133:e477-e489 